\title{
Clinical trials comparing norepinephrine with vasopressin in patients with septic shock: a meta-analysis
}

Fei-Hu Zhou* and Qing Song

\begin{abstract}
Background: The effect of norepinephrine in patients with septic shock remains controversial. We conducted a meta-analysis to compare the mortality rates and benefits of norepinephrine and vasopressin.

Methods: PubMed, EMBASE, and the Cochrane Library database were searched from database inception to December 2013. We selected randomized controlled trials in adults with septic shock and compared norepinephrine with vasopressin. After assessing the heterogeneity of treatment effects across trials using the $P^{2}$ statistic, we used a fixed effects model $(P \geq 0.1)$ and expressed the results as risk ratios (RRs) for dichotomous outcomes or as standardized mean differences (SMDs) for continuous data with 95\% confidence intervals (Cls). Meta-analysis was conducted using Review Manager 5.1 software.

Results: Seven trials $(n=2323)$ met the inclusion criteria. Overall, the mortality rate in these seven trials was $36.2 \%$ (840/2323). There was no difference in mortality following the use of norepinephrine or vasopressin (RR 1.07; 95\%Cl 0.97-1.20; $P=0.19)$. Compared to norepinephrine, vasopressin had no significant effect on heart rate (HR) (SMD $0.21 ; 95 \% \mathrm{Cl}-0.08-0.50 ; P=0.15)$, mean arterial pressure (MAP) (SMD 0.15; $95 \% \mathrm{Cl}-0.15-0.44 ; P=0.33)$, cardiac index (CI) (SMD -0.10; 95\%CI -0.64-0.44; $P=0.73)$, systemic vascular resistance index (SVRI) (SMD 0.15; 95\%CI -0.39-0.70; $P=0.58)$, oxygen delivery $\left(\mathrm{DO}_{2}\right)(\mathrm{SMD}-0.06 ; 95 \% \mathrm{Cl}-0.62-0.49 ; P=0.82)$, oxygen consumption $\left(\mathrm{VO}_{2}\right)(\mathrm{SMD} 0.03$; $95 \% \mathrm{Cl}-0.52-0.59 ; P=0.91)$ or lactic acid (SMD 0.07; 95\% Cl $-0.23-0.36 ; P=0.66)$. No significant heterogeneity was found in these comparisons $(P \geq 0.1)$.
\end{abstract}

Conclusions: There is not sufficient evidence to prove conclusively that norepinephrine is superior to vasopressin in terms of mortality and hemodynamics. The effects of norepinephrine and vasopressin on patients with septic shock require further study in large randomized controlled trials.

Keywords: Norepinephrine, Vasopressin, Sepsis, Shock, Meta-analysis

\section{Background}

Septic shock is one of the most challenging medical problems, and severe sepsis accounts for $20 \%$ of all admissions to intensive care units (ICUs), including 750,000 cases annually in the United States, with a mortality rate ranging from $28 \%$ to $50 \%[1,2]$. The initial goal-directed resuscitation for septic shock typically includes the administration of intravenous fluids and vasopressors. Although norepinephrine is commonly used and is the recommended agent for the treatment

\footnotetext{
* Correspondence: zhoufh301@126.com

Department of Critical Care Medicine, General Hospital of Chinese PLA, Beijing 100853, China
}

of hypotension in volume-resuscitated hyperdynamic septic shock [3], the effect of norepinephrine on patientrelevant outcomes remains controversial. Recent evidence from a large-scale study revealed that there was no significant difference in the mortality rate between patients with septic shock who were treated with dopamine as the first-line vasopressor agent and those who were treated with norepinephrine [4].

Vasopressin is an endogenously released hormone that has recently emerged as an adjunct to catecholamines for patients with septic shock requiring vasopressor support [5]. When compared with norepinephrine, a study has shown that vasopressin treatment in septic shock is 


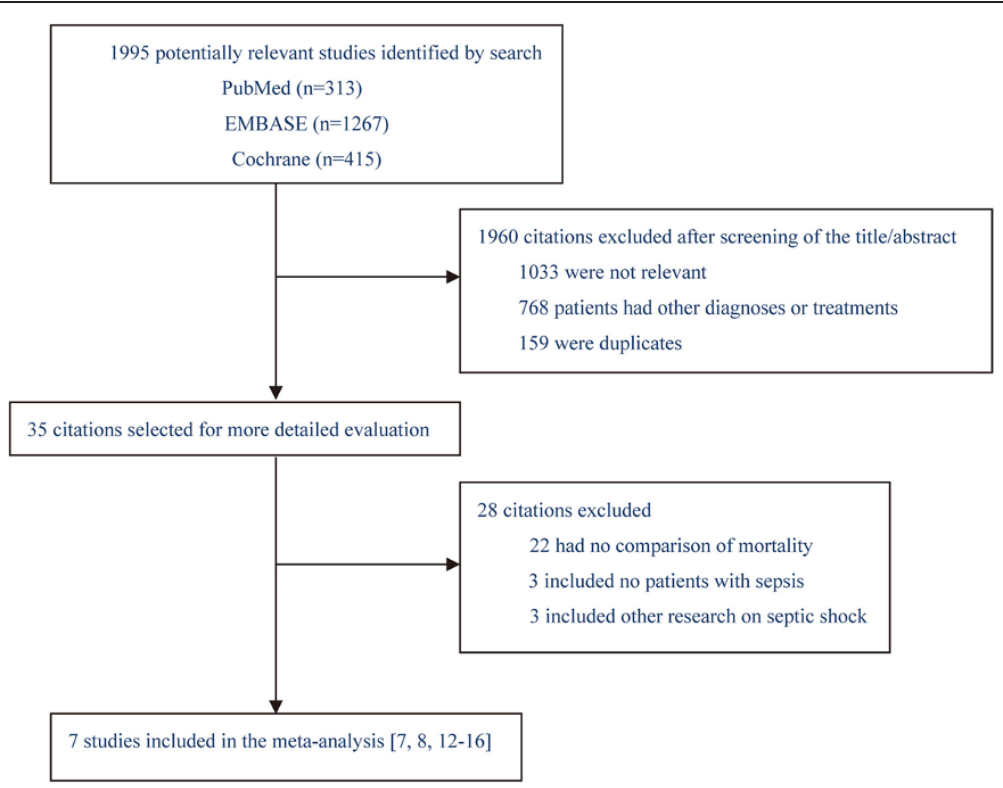

Figure 1 Quorum chart of the study cohort. The search was conducted using the PubMed, EMBASE, and Cochrane Library databases from database inception to December 2013.

associated with a significant reduction in heart rate but no change in cardiac output or other measures of perfusion [6]. Daley et al. revealed that vasopressin was not inferior to norepinephrine for the achievement of a mean arterial pressure (MAP) goal within the first 6 hours following the onset of septic shock [7]. In another study, Russell et al. demonstrated that low-dose vasopressin did not reduce mortality rates when compared with norepinephrine among patients with septic shock who were treated with catecholamine vasopressors [8].

Due to the continuing controversy regarding whether norepinephrine is superior to vasopressin, we performed a meta-analysis to attempt to determine whether norepinephrine is more effective than vasopressin in reducing overall mortality and improving hemodynamics in septic shock.

\section{Methods}

We performed this meta-analysis following the recommendations of the Preferred Reporting Items for Systematic Reviews and Meta-Analyses (PRISMA statement) guidelines [9].

\section{Eligibility criteria and information sources}

We searched for literature in the PubMed (US National Library of Medicine, Bethesda, MD, USA), EMBASE and Cochrane Library databases from database inception to December 2013. The article types were primarily limited to randomized controlled trials (RCTs) that included patients aged older than 18 years. We also scanned the bibliographies of all relevant studies and recent review articles to identify additional citations.

Table 1 Characteristics of the included trials

\begin{tabular}{|c|c|c|c|c|c|c|}
\hline Source & Number of patients & Mean age (years) & Male (\%) & Center & $\begin{array}{l}\text { Mean APACHE II/ } \\
\text { SAPS II/SOFA score }\end{array}$ & Blood pressure $(\mathrm{mmHg})$ \\
\hline Russell JA, 2013 [12] & 394 & 62.8 & $233(59.1)$ & M & 26.8/NR/NR & MAP $<65$ \\
\hline Daley MJ, 2013 [7] & 130 & 58.5 & $69(53.1)$ & $S$ & 27.8/NR/NR & MAP $<65$ \\
\hline Gordon AC, 2010 [13] & 778 & 61.8 & $475(61.0)$ & M & 27.1/NR/NR & MAP 72.7 (NE maintenance) \\
\hline Russell JA, 2009 [14] & 190 & 61 & $116(61.1)$ & M & 26.5/NR/NR & MAP $<60$ \\
\hline Morelli A, 2009 [15] & 45 & 65.7 & $33(73.3)$ & $\mathrm{S}$ & $N R / 60 / N R$ & MAP $<65$ \\
\hline Russell JA, 2008 [8] & 778 & 60.6 & $475(61.1)$ & M & 27.1/NR/NR & MAP 72.5 (vasopressor maintenance) \\
\hline Lauzier F, 2006 [16] & 23 & 54.7 & $14(60.9)$ & M & $23.2 / N R / 8.9$ & $M A P<60$ \\
\hline
\end{tabular}

APACHE, acute physiology and chronic health evaluation; SAPS, simplified acute physiology score; SOFA, sequential organ failure assessment; MAP, mean arterial pressure; $S$, single-center trial; $M$, multicenter trial; NE, norepinephrine; NR, not reported. 
Table 2 Quality assessment of the six randomized controlled trials included in the meta-analysis

\begin{tabular}{|c|c|c|c|c|c|}
\hline Source & Randomization & Allocation concealment & Blinding & Description of withdrawals and dropouts & Jadad score \\
\hline Russell JA, 2013 [12] & Yes & Uncertain & Yes & Yes & 3 \\
\hline Gordon AC, 2010 [13] & Yes & Adequate & Yes & Yes & 5 \\
\hline Russell JA, 2009 [14] & Yes & Adequate & Yes & Yes & 5 \\
\hline Morelli A, 2009 [15] & Yes & Adequate & Uncertain & Yes & 3 \\
\hline Russell JA, 2008 [8] & Yes & Adequate & Yes & Yes & 5 \\
\hline Lauzier F, 2006 [16] & Yes & Adequate & Uncertain & Yes & 3 \\
\hline
\end{tabular}

\section{Search strategy}

We used medical subject heading (MeSH) terms and text words with a Boolean strategy. Cross-searching was performed based on the following 2 categories: (1) different vasopressors ("norepinephrine" OR "vasopressin"); (2) disease ("sepsis" OR "infection" OR "septic shock" OR "shock" OR "systemic inflammatory response syndrome" OR "SIRS"). The limits placed on the literature searches were "human" and "English".

\section{Study selection}

The study selection was performed by two independent investigators (F.Z. and Q.S.). Studies that compared mortality between norepinephrine and vasopressin use in patients (aged $\geq 18$ years) with septic shock were evaluated and included.

\section{Data extraction}

Raw data were extracted using a standard form for each study, which included the study design, year of publication, total number of patients, and patient characteristics. The main endpoint was 28-day mortality. If mortality was assessed at several time points or only at an undetermined time point in a study, we used data from the last followup or the only undetermined time point.

\section{Quality assessment}

The quality of each study included in the meta-analysis was assessed using the Jadad score [10], including the proper conduct of randomization, concealment of treatment allocation, similarity of treatment groups at baseline, clinician blinding, and the description of withdrawals and dropouts.

\section{Statistical analysis}

Statistical analyses were performed using Review Manager, version 5.1 (RevMan, The Cochrane Collaboration, Oxford, the United Kingdom). After assessing for the heterogeneity of treatment effects across trials using the $I^{2}$ statistic [11], we used a fixed effects model $(P \geq 0.1)$. The results were expressed as risk ratios (RRs) for dichotomous outcomes or standardized mean differences (SMDs) for continuous data with 95\% confidence intervals (CIs), and $P<0.05$ was considered significant. Publication bias was assessed using funnel plots.

\section{Results}

\section{Study selection}

A total of 1995 studies were identified. We retrieved 35 articles for detailed evaluation, of which 28 were excluded (Figure 1). Seven trials (2323 patients) met the criteria for inclusion $[7,8,12-16]$. All studies compared the effects of norepinephrine and vasopressin in patients with

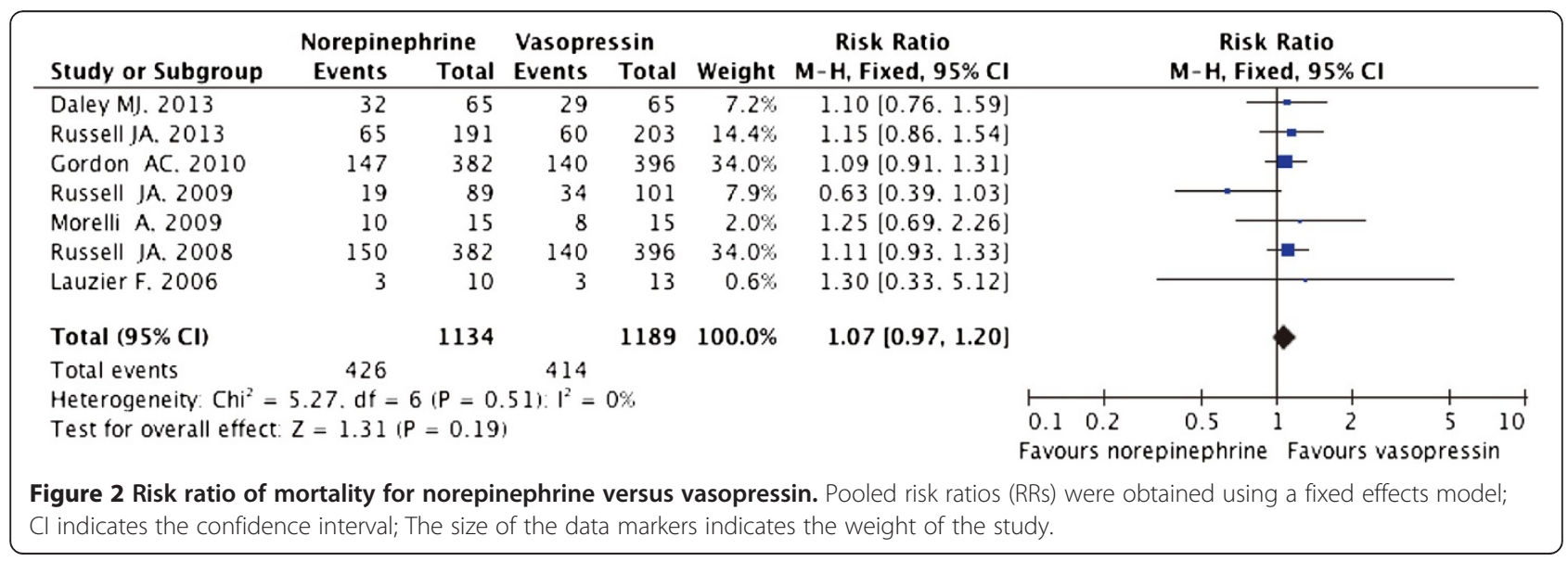


septic shock using a primary outcome such as survival, hemodynamics, or acute physiology and chronic health evaluation (APACHE) II score (Table 1).

\section{Study characteristics}

Five multicenter studies $[8,12-14,16]$ and two single-center studies $[7,15]$ were identified. The characteristics of the included trials are shown in Table 1 . These trials were reported between 2006 and 2013, and the mean age of the study participants ranged between 54.7 and 62.8 years. The proportion of men ranged from $53.1 \%$ to $61.1 \%$. The mean APACHE II score was between 23.2 and 27.8. All patients with sepsis or septic shock were diagnosed according to the American College of Chest Physicians/Society of Critical Care Medicine Consensus Conference criteria [17].

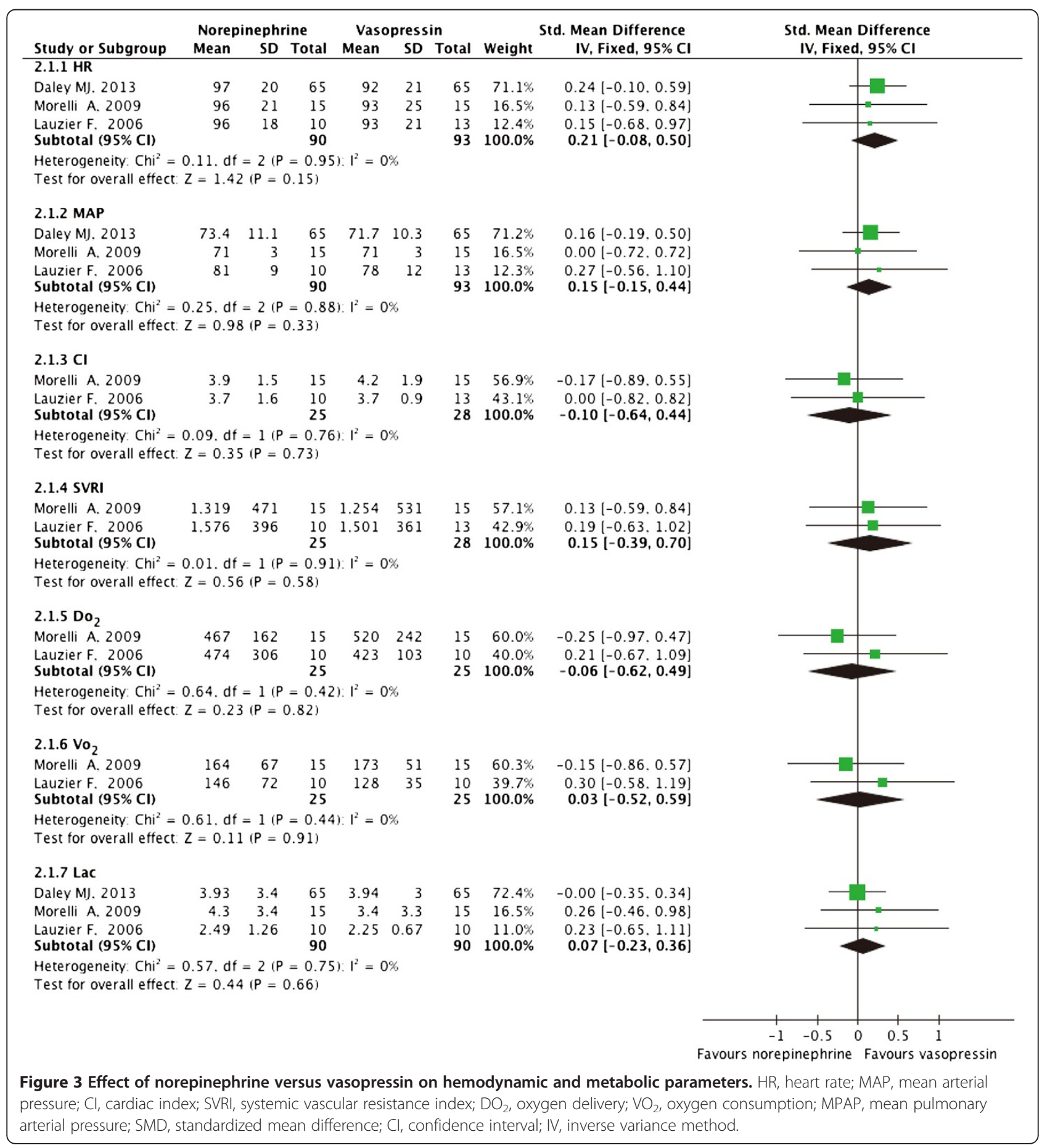




\section{Risk of bias within studies}

Six of the citations included [8,12-16] were randomized controlled trials, and one was a cohort study [7]. Blinding was performed in four studies [8,12-14]. The mean Jadad score of the six randomized controlled trials was 4 (Table 2).

\section{Effect of norepinephrine versus vasopressin on mortality}

The mortality rate in the seven trials was $36.2 \%$ (840/ 2323). No difference in mortality was identified when comparing norepinephrine and vasopressin (RR 1.07; 95\%CI 0.97-1.20; $\mathrm{P}=0.19)$. No significant heterogeneity was found in this comparison $\left(I^{2}=0 \%, \mathrm{P}=0.51\right)$ and the fixed effects model was used (Figure 2). Because one trial [7] was a cohort study, we also performed a metaanalysis of the other six trials [8,12-16]. Similarly, no difference in mortality was found when comparing these two groups (RR 1.07; 95\%CI 0.96-1.20; $\mathrm{P}=0.22$; $\left.I^{2}=5 \%, \mathrm{P}=0.39\right)$.

\section{Effect of norepinephrine versus vasopressin on hemodynamic and metabolic parameters}

Compared to norepinephrine, vasopressin had no significant effect on heart rate (HR) (SMD 0.21; 95\%CI -0.08$0.50 ; P=0.15$ ), MAP (SMD 0.15; 95\%CI -0.15-0.44; $P=0.33$ ), cardiac index (CI) (SMD -0.10; 95\%CI -0.64$0.44 ; P=0.73)$, systemic vascular resistance index (SVRI) (SMD 0.15; 95\%CI -0.39-0.70; $P=0.58)$, oxygen delivery $\left(\mathrm{DO}_{2}\right)(\mathrm{SMD}-0.06 ; 95 \% \mathrm{CI}-0.62-0.49 ; P=0.82)$, oxygen consumption $\left(\mathrm{VO}_{2}\right)(\mathrm{SMD} 0.03 ; 95 \% \mathrm{CI}-0.52-0.59$; $P=0.91)$ or lactic acid (SMD, 0.07; 95\%CI $-0.23-0.36$; $P=0.66)$. No significant heterogeneity was found in these comparisons $(P \geq 0.1$, Figure 3$)$.

\section{Publication bias analyses}

Publication bias was evaluated using a funnel plot, and the primary comparisons of mortality are presented. The funnel plots of this primary outcome did not suggest major asymmetry, indicating no significant publication bias (Figure 4).

\section{Discussion}

Seven trials including 2323 patients with septic shock that compared the use of norepinephrine to vasopressin were identified and included in this review. The main results revealed that the survival of patients treated with norepinephrine was not significantly different from those treated with vasopressin. Furthermore, there was also no evidence indicating that norepinephrine is superior to vasopressin in improving hemodynamics.

Vasopressors should be initiated in patients with septic shock if fluid resuscitation fails to restore adequate arterial pressure and organ perfusion, and the effects of vasopressors differ based on the targeted adrenergic receptors, resulting in heterogeneity of their physiological effects [18]. Although both dopamine and norepinephrine are recommended as first-line vasopressor agents in the treatment of septic shock [3], vasopressin, which is a peptide hormone released by the pituitary in response to decreased intravascular volume, has been used in patients with septic shock $[18,19]$. In a multi-center double-blind randomized controlled trial of vasopressin versus norepinephrine in adult patients who had septic shock, Gordon et al. revealed that patients with septic shock who were at risk of kidney injury had reduced progression to renal failure and reduced 28-day mortality when treated with vasopressin in comparison to those treated with norepinephrine [13]. However, our metaanalysis did not find a significant difference in mortality

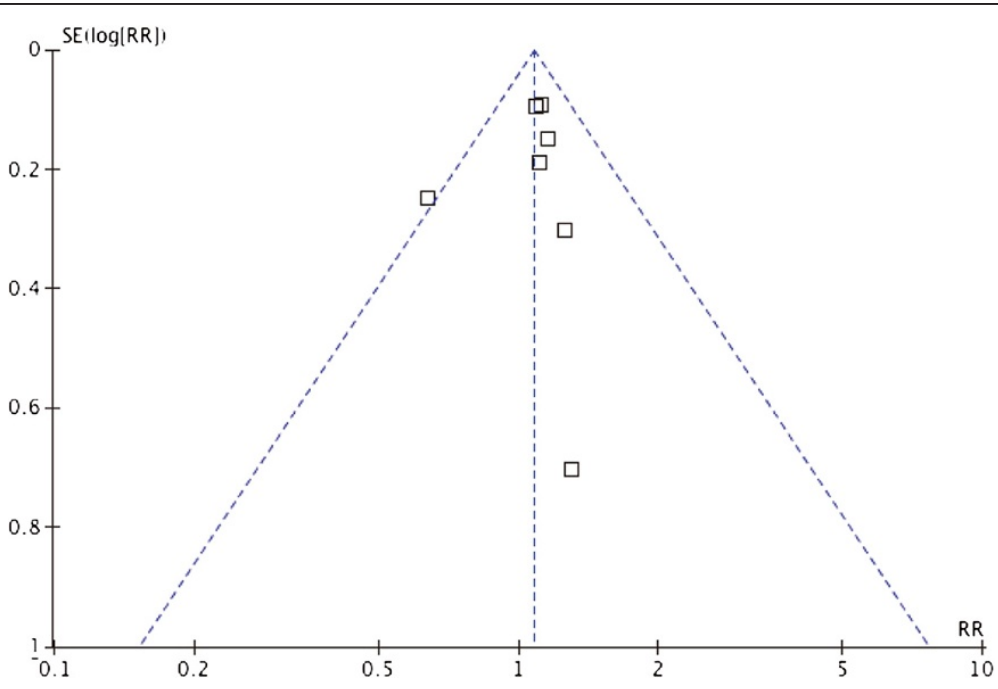

Figure 4 Assessment of publication bias using a funnel plot. 
between norepinephrine and vasopressin, which was consistent with more recent randomized clinical trials $[8,15,16]$. It is likely that no single pressor has been definitively shown to have a mortality benefit over another in patients with septic shock. It is possible that a continuous infusion of low-dose vasopressin, when given as first-line vasopressor agent in septic shock, is effective in reversing sepsis-induced arterial hypotension and reducing norepinephrine requirements.

For septic patients, once the inflammatory response has been induced, a marked decrease in the SVRI results from arterial and venous dilation, which is accompanied by leakage of plasma into the extravascular space, leading to relative hypovolemia [20]. Recent randomized clinical trials demonstrated that survivors of septic shock had greater decreases in cytokines, chemokines and growth factors in early septic shock. Furthermore, vasopressin decreased 24-hour plasma cytokine levels more than did norepinephrine [12]. In the present study, we compared norepinephrine to vasopressin and found no significant differences in HR, MAP, CI, or SVRI. This was not consistent with a previous trial [16], in which vasopressin was reported to increase the SVRI and decrease the CI when compared with baseline, whereas norepinephrine did not [16]. The hemodynamic impact of norepinephrine on the treatment of septic shock compared to vasopressin, however, requires further evaluation in randomized clinical trials.

For patients with septic shock, it is imperative to restore adequate perfusion pressure and oxygen delivery. It is evident that inadequate systemic hemodynamics, i.e., systemic $\mathrm{DO}_{2}$ and $\mathrm{VO}_{2}$, can impair splanchnic blood flow and oxygenation [21]. Although increased renal circulation and splanchnic blood flow have been reported in cases of hyperdynamic septic shock treated with norepinephrine [22-24], no significant differences in $\mathrm{DO}_{2}, \mathrm{VO}_{2}$ or lactate were found between norepinephrine and vasopressin in our meta-analysis. Because one of the rationales for catecholamine administration in septic patients is to increase $\mathrm{DO}_{2}$ due to the relationship between $\mathrm{DO}_{2}$ and $\mathrm{VO}_{2}$ [25], norepinephrine may therefore be questionable as a preferential treatment when compared with vasopres$\sin$ in this context.

There are some limitations to this meta-analysis. First, although the mean Jadad score of the included trials was 4 , indicating that most of the trials were of high quality, one cohort study was included in this meta-analysis, which may limit the strength of the analysis. Second, although seven trials were included in the analysis, the actual sample size for specific comparisons in subgroup analyses was small, and publication bias was only evaluated using a funnel plot with seven studies, which may have affected the findings. The effects of norepinephrine and vasopressin in patients with septic shock require further evaluation in large-scale randomized controlled trials.

\section{Conclusions}

In conclusion, pooled results of seven trials show that there is not sufficient evidence to prove conclusively that norepinephrine is superior to vasopressin in terms of mortality and hemodynamics. The effects of norepinephrine and vasopressin on patients with septic shock require further study in large randomized controlled trials.

\section{Abbreviations}

ICU: Intensive care unit; RCTs: Randomized controlled trials; MeSH: Medical subject heading; Cl: Confidence interval; HR: Heart rate; MAP: Mean arterial pressure; Cl: Cardiac index; SVRI: Systemic vascular resistance index; MPAP: Mean pulmonary arterial pressure; SMD: Standardized mean difference; IV: Inverse variance.

\section{Competing interest}

The authors declare that they have no competing interests.

\section{Author contributions}

All authors had full access to all of the data in the study and take responsibility for the integrity of the data and the accuracy of the data analysis. FZ is the overall coordinator of the study, and his work included the study design, acquisition of data, analysis and interpretation of data, drafting of the manuscript, statistical analysis, and critical revision of the manuscript for important intellectual content. The work that QS performed included the acquisition of data, analysis and interpretation of data, and statistical analysis. Both authors read and approved the final manuscript.

\section{Received: 17 April 2014 Accepted: 17 April 2014}

Published: 1 May 2014

\section{References}

1. Levy MM, Dellinger RP, Townsend SR, Linde-Zwirble WT, Marshall JC, Bion J, Schorr C, Artigas A, Ramsay G, Beale R, Parker MM, Gerlach H, Reinhart K, Silva E, Harvey M, Regan S, Angus DC: Surviving Sepsis Campaign: The surviving sepsis campaign: results of an international guideline-based performance improvement program targeting severe sepsis. Crit Care Med 2010, 38:367-374

2. Angus DC, Linde-Zwirble WT, Lidicker J, Clermont G, Carcillo J, Pinsky MR: Epidemiology of severe sepsis in the United States: analysis of incidence, outcome, and associated costs of care. Crit Care Med 2001, 29:1303-1310.

3. Dellinger RP, Levy MM, Carlet JM, Bion J, Parker MM, Jaeschke R, Reinhart K, Angus DC, Brun-Buisson C, Beale R, Calandra T, Dhainaut JF, Gerlach H, Harvey M, Marini JJ, Marshall J, Ranieri M, Ramsay G, Sevransky J, Thompson BT, Townsend S, Vender JS, Zimmerman JL, Vincent JL: International Surviving Sepsis Campaign Guidelines Committee; American Association of CriticalCare Nurses; American College of Chest Physicians; American College of Emergency Physicians; Canadian Critical Care Society; European Society of Clinical Microbiology and Infectious Diseases; European Society of Intensive Care Medicine; European Respiratory Society; International Sepsis Forum; Japanese Association for Acute Medicine; Japanese Society of Intensive Care Medicine; Society of Critical Care Medicine; Society of Hospital Medicine; Surgical Infection Society; World Federation of Societies of Intensive and Critical Care Medicine: Surviving Sepsis Campaign: international guidelines for management of severe sepsis and septic shock: 2008. Crit Care Med 2008, 36:296-327.

4. De Backer D, Biston P, Devriendt J, Madl C, Chochrad D, Aldecoa C, Brasseur A Defrance P, Gottignies P, Vincent JL: SOAP II Investigators: Comparison of dopamine and norepinephrine in the treatment of shock. N Engl J Med 2010, 362:779-789.

5. Personett HA, Stollings $J \mathrm{~L}$, Cha SS, Oyen L: Predictors of prolonged vasopressin infusion for the treatment of septic shock. J Crit Care 2012, 27(318):e7-e12.

6. Gordon AC, Wang N, Walley KR, Ashby D, Russell JA: The cardiopulmonary effects of vasopressin compared with norepinephrine in septic shock. Chest 2012, 142:593-605. 
7. Daley MJ, Lat I, Mieure KD, Jennings HR, Hall JB, Kress JP: A comparison of initial monotherapy with norepinephrine versus vasopressin for resuscitation in septic shock. Ann Pharmacother 2013, 47:301-310.

8. Russell JA, Walley KR, Singer J, Gordon AC, Hébert PC, Cooper DJ, Holmes CL, Mehta S, Granton JT, Storms MM, Cook DJ, Presneill JJ: Ayers D; VASST Investigators: Vasopressin versus norepinephrine infusion in patients with septic shock. N Engl J Med 2008, 358:877-887.

9. Moher D, Liberati A, Tetzlaff J, Altman DG, PRISMA Group: Preferred reporting items for systematic reviews and meta-analyses: the PRISMA statement. Int J Surg 2010, 8:336-341.

10. Jadad AR, Moore RA, Carroll D, Jenkinson C, Reynolds DJ, Gavaghan DJ, McQuay HJ: Assessing the quality of reports of randomized clinical trials: is blinding necessary? Control Clin Trials 1996, 17:1-12.

11. Higgins JP, Thompson SG, Deeks JJ, Altman DG: Measuring inconsistency in meta-analyses. BMJ 2003, 327:557-560

12. Russell JA, Fjell C, Hsu JL, Lee T, Boyd J, Thair S, Singer J, Patterson AJ, Walley KR: Vasopressin compared with norepinephrine augments the decline of plasma cytokine levels in septic shock. Am J Respir Crit Care Med 2013, 188:356-364.

13. Gordon AC, Russell JA, Walley KR, Singer J, Ayers D, Storms MM, Holmes CL, Hébert PC, Cooper DJ, Mehta S, Granton JT, Cook DJ, Presneill Jj: The effects of vasopressin on acute kidney injury in septic shock. Intensive Care Med 2010, 36:83-91.

14. Russell JA, Walley KR, Gordon AC, Cooper DJ, Hébert PC, Singer J, Holmes CL, Mehta S, Granton JT, Storms MM, Cook DJ, Presneill JJ: Dieter Ayers for the Vasopressin and Septic Shock Trial Investigators: Interaction of vasopressin infusion, corticosteroid treatment, and mortality of septic shock. Crit Care Med 2009, 37:811-818.

15. Morelli A, Ertmer C, Rehberg S, Lange M, Orecchioni A, Cecchini V, Bachetoni A, D'Alessandro M, Van Aken H, Pietropaoli P, Westphal M: Continuous terlipressin versus vasopressin infusion in septic shock (TERLIVAP): a randomized, controlled pilot study. Crit Care 2009, 13:R130

16. Lauzier F, Lévy B, Lamarre P, Lesur O: Vasopressin or norepinephrine in early hyperdynamic septic shock: a randomized clinical trial. Intensive Care Med 2006, 32:1782-1789.

17. Bone RC, Balk RA, Cerra FB, Dellinger RP, Fein AM, Knaus WA, Schein RM, Sibbald WJ: Definitions for sepsis and organ failure and guidelines for the use of innovative therapies in sepsis. The ACCP/SCCM Consensus Conference Committee. American College of Chest Physicians/Society of Critical Care Medicine. Chest 1992, 101:1644-1655.

18. Hollenberg SM: Inotrope and vasopressor therapy of septic shock. Crit Care Clin 2009, 25:781-802.

19. Parrillo JE: Septic shock-vasopressin, norepinephrine, and urgency. N Engl J Med 2008, 358:954-956.

20. Leone M, Martin C: Vasopressor use in septic shock: an update. Curr Opin Anaesthesiol 2008, 21:141-147.

21. Guérin JP, Levraut J, Samat-Long C, Leverve X, Grimaud D, Ichai C: Effects of dopamine and norepinephrine on systemic and hepatosplanchnic hemodynamics, oxygen exchange, and energy balance in vasoplegic septic patients. Shock 2005, 23:18-24.

22. Murphey ED, Traber DL: Cardiopulmonary and splanchnic blood flow during 48 hours of a continuous infusion of endotoxin in conscious pigs: a model of hyperdyanmic shock. Shock 2000, 13:224-229.

23. Träger $\mathrm{K}$, Radermacher $\mathrm{P}$, Rieger KM, Vlatten A, Vogt J, Iber T, Adler J, Wachter U, Grover R, Georgieff M, Santak B: Norepinephrine and nomega-monomethyl-Larginine in porcine septic shock: effects on hepatic $\mathrm{O}_{2}$ exchange and energy balance. Am J Respir Crit Care Med 1999, 159:1758-1765.

24. Meier-Hellmann A, Specht M, Hannemann L, Hassel H, Bredle DL, Reinhart K: Splanchnic blood flow is greater in septic shock treated with norepinephrine than in severe sepsis. Intensive Care Med 1996, 22:1354-1359.

25. De Backer D, Zhang H, Cherkhaoui S, Borgers M, Vincent JL: Effects of dobutamine on hepato-splanchnic hemodynamics in an experimental model of hyperdynamic endotoxic shock. Shock 2001, 15:208-214.

doi:10.1186/2054-9369-1-6

Cite this article as: Zhou and Song: Clinical trials comparing norepinephrine with vasopressin in patients with septic shock: a meta-analysis. Military Medical Research 2014 1:6.

\section{Submit your next manuscript to BioMed Central and take full advantage of:}

- Convenient online submission

- Thorough peer review

- No space constraints or color figure charges

- Immediate publication on acceptance

- Inclusion in PubMed, CAS, Scopus and Google Scholar

- Research which is freely available for redistribution

Submit your manuscript at www.biomedcentral.com/submit
() Biomed Central 